\title{
TEMPO E DEMOCRACIA: UMA PROPOSTA DE APROXIMAÇÃO DO PENSAMENTO DE PAULO FREIRE COM A CRONOBIOLOGIA
}

\author{
POR LUIZ MENNA-BARRETO' \\ CLÁUDIA ESPÍRITO-SANTO
}

\section{RESUMO}

Neste artigo, propomos reflexões sobre possíveis implicações da contribuição de Paulo Freire para uma área relativamente recente da Biologia, a Cronobiologia, cujo tema central é a organização temporal dos seres vivos, incluídos os seres humanos. Articulações com outros pensadores são propostas.

\section{PALAVRAS-CHAVE}

Temporalidade; Cronobiologia; Ritmos, Ritmanálise; Gestão Democrática; Horários Escolares

\begin{abstract}
In this article we invite reflections on possible implications of Paulo Freire's contributions to a relatively recent area of Biology, Chronobiology, where the temporal organization of living beings, including humans, occupies a central space. Articulations with other authors are proposed.
\end{abstract}

\section{KEYWORDS}

Temporality; Chronobiology; Rhythm; Rhythmanalysis; Democratic School Management; School Schedules

\footnotetext{
'Escola de Artes, Ciências e Humanidades, USP.

${ }^{2}$ Mestra pelo Programa de Pós-Graduação em Estudos Culturais EACH/USP.
} 


\section{Apresentação}

As contribuições de Paulo Freire para o conhecimento são reconhecidas internacionalmente, e o reflexo disso é a ampla variedade de pesquisas, trabalhos e textos que manejam seu rico referencial teórico, com abordagens temáticas diversas, em praticamente todas as áreas. Nas licenciaturas, são inúmeros os trabalhos que relacionam o pensamento freireano ao ensino de disciplinas específicas, e há uma vasta pesquisa no campo do ensino de ciências, em geral, e também na Biologia. (KRASILCHIK, 1987) Nossa pretensão aqui é ampliar esse reconhecimento através da associação do pensamento freireano a uma área relativamente recente do conhecimento na Biologia, a Cronobiologia, que tem como foco central a organização temporal dos seres vivos.

Inspirados na leitura da obra de Henri Lefebvre, Élements de Ritmanalyse, publicada na França em 1992 (LEFEBVRE, 1992) e traduzida para o inglês em 2004 (LEFEVBRE, 2004), estabelecemos uma associação entre esses autores a partir da ideia de ritmo. Lefebvre, no segundo capítulo da obra citada, afirma que todas as coisas, vivas ou não vivas, apresentam um ritmo, que pode ser considerado rápido ou lento. Dessa forma, há sempre uma dinâmica (uma ritmicidade) no universo. Na proposta de Lefebvre, a identificação dos ritmos presentes em uma sociedade permite/convida o leitor a uma análise da qual emergem relações de poder nessa sociedade, especialmente no plano da atividade cotidiana vigente. Apoiados nessa leitura, estamos propondo uma convergência entre Lefebvre e Paulo Freire para a reflexão sobre horários escolares, entre outros tempos sociais, até onde sabemos inédita, que constitui nosso objetivo neste artigo.

\section{Processos históricos e identidade temporal}

Nossas vivências temporais como humanos acabam se constituindo em parâmetro de comparação com os outros ritmos presentes na natureza, o que leva algumas pessoas a entender uma rocha como algo imutável, que sempre foi e sempre 
será igual. Lefebvre (2004) critica essa leitura ingênua, ideológica, argumentando que a rocha tem, sim, história no plano geológico, com passado e futuro que começam a ser desvendados na ciência contemporânea. Quando lemos textos atuais sobre o processo de destruição do meio ambiente, é evidente que estamos diante de constatações de uma dinâmica que autoriza previsões de catástrofes futuras. É com base nessa mesma dinâmica que Humberto Maturana e Francisco Varela (1974) propuseram o conceito de autopoiese, levando para o conhecimento no campo biológico a ideia de essência dinâmica dos sistemas vivos, os quais, assim como a rocha, têm passado, presente e futuro. Herbert Gomes da Silva e Maria Elena Infante-Malachias (2017) se apoiam nas reflexões desses pensadores chilenos e, inspirados na abordagem de Paulo Freire para a temporalidade, propõem um ensino de Biologia por eles denominado Biologia da autonomia.

Nesta contribuição, consideramos, igualmente, o pensamento desses autores, com abordagem freireana, acrescentando o conhecimento proveniente da Cronobiologia, os conceitos estabelecidos nesse campo e as contribuições de pesquisas sobre ritmicidade biológica para uma possível leitura crítica dos tempos praticados nas sociedades capitalistas contemporâneas e como esses tempos repercutem nos tempos escolares. Aqui a contribuição de Lefebvre é fundamental, pois esse autor marxista de grande relevância no século XX, mais conhecido por seus trabaIhos dedicados à análise do espaço urbano, fez uma inter-relação analítica entre espaço e tempo para compreender a vida cotidiana. Com base nessa proposta, ele observa como as rotinas diárias são estabelecidas no espaço urbano por meio de repetições, com a criação de demanda por hora, a organização dos sistemas de transporte em períodos curtos, entre outras. (LEFEBVRE, 2004)

Paulo Freire entra nesse cenário, a princípio, por dois planos que apresentamos aqui como metáfora de respostas a duas perguntas-chave: 1) Como ocorre a produção do conhecimento no campo da Biologia?; 2) Como o ambiente escolar é organizado para a (re)produção do conhecimento? Esses dois planos são interdependentes e aparecem simultaneamente no ambiente escolar. Trata-se de refletir sobre suas raízes e fundamentações, que, na maioria das vezes, negligenciam a dimensão temporal. 
Em geral, somos apresentados à vida nas primeiras aulas de ciências através de um desenho esquemático de uma célula representada em círculos concêntricos. Quase sempre se omitem informações fundamentais para caracterizar tal representação, entre elas a de que a célula deve estar morta e corada para ser vista através do microscópio, e também se omite o fato de que alguém a colocou sob a lente. Omite-se, assim, o processo de criação do conhecimento por meio da intervenção humana, pois não se trata da simples representação da imagem de uma célula, mas da construção dessa imagem. Isso nos permite ler a representação como uma abstração na qual o processo de construção fica oculto, o que contribui para o processo de alienação do corpo e da materialidade da vida, da sua historicidade, pois as raízes das coisas e dos fenômenos foram cortadas.

No plano do conhecimento isso traz implicações importantes, afastando a dinâmica dos processos vitais do foco dos conceitos propostos. Essas limitações abrangem, inclusive, as noções que sustentam atualmente os calendários escolares, justamente por não considerar a temporalidade inscrita nos professores, pais e estudantes. Paulo Freire nos convida a uma revisão dos conceitos e práticas. Exploraremos aqui a dimensão temporal. O tempo está presente na obra de Paulo Freire como uma criação humana em sua concepção, adequação e uso, e ele critica abordagens conceituais que não observam as relações temporais e também aquelas que apresentem o tempo dos acontecimentos históricos apenas de forma linear. Nesse aspecto, sua abordagem converge com a proposta de ritmanálise, de Lefebvre (2004), que será apresentada adiante.

No que se refere à prática pedagógica, Freire acredita no tempo vivido (do sujeito) apresentado como um ritmo próprio e singular, "que se costura na grande ciranda de outros seres semelhantes, cujas temporalidades precisam ser entretecidas numa comunidade de destinos e de lutas coletivas". (PASSOS, 2018, p. 449) Esse pensamento também se aproxima muito do que Lefbvre (2004) define como polirritmia e eurritmia. Paulo Freire defende ainda o que chama de "paciência história", que precisa ser cultivada de forma inteligente e inquieta, pelo educador, para não quebrar processos pessoais e sociais de humanização em relação aos seus alunos. (PASSOS, 2018) 
Assim como o ser humano parte dos próprios ritmos para compreender o universo e estabelecer critérios marcados por um recorte ideológico (LEFEBVRE, 2004), o ritmo social imposto no ambiente escolar e criticado por Paulo Freire pode criar classificações entre os indivíduos com base em parâmetros estabelecidos nas relações de poder e dominação da sociedade em que esta escola está inserida. A partir de tais parâmetros, as pessoas passam a ser consideradas rápidas ou lentas, habilitadas ou inabilitadas, competentes ou incompetentes e, em última instância, adequadas ou inadequadas ao convívio no ambiente escolar.

O tema diversidade e inclusão escolar, bastante contemplado em pesquisas científicas na Educação, e um mote na obra freireana, tem relação com um dos temas mais visitados na Cronobiologia contemporânea, que é justamente o das diferenças de comportamento entre indivíduos, no caso, as preferências mais matutinas ou mais vespertinas, também conhecidas como cronotipos. Porém, a maioria dos autores na Cronobiologia parte da premissa de que as características temporais de um indivíduo são fixas, marcadas geneticamente.

Ora, essa premissa não se sustenta mais, dadas as demonstrações de que essas preferências mudam ao longo da vida - hoje o que merece ser investigado são a história da construção individual dessas preferências e os fatores que contribuem para a sua transformação. Defendemos que todos apresentam subjetividades na forma como se organizam no tempo com base em características biológicas, sociais, culturais e psicológicas, o que temos chamado de identidade temporal, e entendemos que a abordagem de Paulo Freire engloba também essa identidade, quando ele propõe o respeito à singularidade temporal dos sujeitos no processo educativo no intuito de não interromper processos históricos de sua formação como ser humano.

Ao longo da vida, construímos nossos recortes temporais singulares - o que vale para a espécie é essa capacidade de incorporar experiências em geral, e nunca as experiências singulares. Se ocorresse essa assimilação coletiva, seríamos todos iguais, e justamente no plano individual é que podemos falar de construção singular. Quando mudamos de turno de trabalho ou viajamos para outro fuso horário, por exemplo, somos desafiados a nos adaptar a uma nova temporalidade, e 
essa adaptação, que sabidamente não é imediata, acaba ocorrendo. Os problemas surgem quando esses desafios se repetem com frequência, gerando o que temos chamado de atritos temporais, caracterizados por dessincronizações internas e externas e pelas patologias daí decorrentes, como é o caso das depressões.

E no que se constituem os desafios e atritos temporais no ambiente escolar? Acordar cedo para entrar em aula às 7 horas da manhã, nos ensinos fundamental e médio, pode ser um desafio para jovens que estudavam em outros horários escolares e tiveram de mudar para o turno da manhã. O desafio propriamente dito consiste em conseguir dormir o sono suficiente, com a mesma duração que em etapas anteriores da vida. Para aqueles que já vinham acordando cedo, o desafio não é importante, a privação de sono é pequena ou inexistente. Mas, para os que não conseguem ajustar seus horários à nova rotina, o desafio torna-se crônico e com um custo importante: alterações de humor, dificuldades de concentração/atenção e prejuízo na memorização. (CARVALHO-MENDES, 2019) No desajuste que se mantém por muito tempo, podemos falar em atrito temporal.

O padrão de sono e vigília que se instala nos casos em que o atrito é evidente tende a apresentar sono encurtado nos dias de semana e sono estendido no fim de semana. Alguns autores têm chamado esse padrão de "jet lag social", expressão equivocada a nosso ver. O equívoco deve-se à aparente coincidência de sintomas entre o que acontece com os estudantes e o que acontece com viajantes que atravessam fusos horários (origem da expressão). Em ambos ocorre um desconforto de duração variável - nos viajantes que permanecem no local de destino, a adaptação acaba ocorrendo, sobretudo quando há imersão profunda nas rotinas desse novo local. Já nos estudantes cujos hábitos não são modificados - e o uso de eletrônicos à noite é muito comum entre adolescentes, dificultando adiantar o horário de início do sono noturno - o desajuste temporal permanece. A diferença entre os dois casos reside justamente no entorno social e na história temporal, a cronicidade ou não desses desajustes se constituindo, assim, em explicação e diferenciação do fenômeno que, embora se manifeste de modo similar, se diferencia justamente no tempo. 


\section{Horários escolares e gestão democrática}

Uma discussão atual sobre o horário de início das aulas para adolescentes, com o atraso, em geral de uma hora, proposto e adotado em alguns países e eventualmente contemplada no Brasil, foi publicada na página eletrônica da National Sleep Foundation?3. A proposta de atraso está apoiada em dados sobre privação de sono em uma população de adolescentes e visa atenuar os efeitos da privação no desempenho escolar. Constatações mais recentes mostram que o atraso no início das aulas acaba acompanhado também por um atraso equivalente nos horários de início do sono, ou seja, mantem-se a privação, além de acarretar em problemas nas rotinas familiares (LOUZADA e MENNA-BARRETO, 2007).

A definição do horário de início das aulas e do calendário de aulas e férias deve ser objeto de negociação entre todas as partes envolvidas, alunos pais e professores, seja diretamente, seja através de seus representantes. Devemos assumir esse processo em sua complexidade, nunca redutível a aspectos pontuais. Evoquemos aqui a proposta de ritmanálise de Lefebvre (2004, p. 21-22) com a sua análise triádica do cotidiano.

Para esse autor, a análise clássica isola um elemento ou um aspecto do objeto, por isso é reducionista por definição; as análises estruturais lançam luzes sobre termos opostos, dois a dois, a fim de estudar suas relações e interações; a análise dialética separa dois termos em interação para uma síntese (que seria o terceiro termo); já a análise triádica vincula três termos, mas os mantém distintos, ou seja, sem fundi-los em uma síntese. Segundo Lefebvre, isso fornece a estrutura para a análise de casos particulares, portanto, reais, como história e vida de indivíduos ou grupos de indivíduos.

Já a noção de ritmo, segundo Lefebvre (2004), requer considerações complementares: polirritmia, eurritmia e arritmia. Para ele, para a verificação da polirritmia, basta consultar o corpo de um indivíduo e nele o cotidiano será revelado

\footnotetext{
${ }^{3}$ Disponível em: https://www.sleepfoundation.org/articles/school-start-time-and-sleep. Acesso em 10 set. 2019.
} 
como um espírito. No caso da eurritmia, os ritmos se unem no estado de saúde, em condições normais (ou seja, normatizadas) na vida cotidiana; e quando os ritmos são discordantes existe sofrimento, quer dizer, um estado patológico do qual a arritmia, em geral, é ao mesmo tempo sintoma, causa e efeito. (LEFEBVRE, 2004, p. 25)

Na gestão da vida escolar, devemos ter sempre presentes as recomendações de Paulo Freire de gestão democrática, que inclui - ao invés de afastar todos os envolvidos no processo. Na época em que esteve à frente da Secretaria Municipal de Educação da Prefeitura de São Paulo, participando de uma mesa de debates em abril de 1992, Paulo Freire tomou conhecimento de conceitos científicos sobre ritmicidade biológica em crianças e a maior probabilidade de desajuste com alguns turnos escolares. A esse respeito, Paulo Freire disse que "O problema de nossa sociedade é uma dessincronização com a democracia." "Freire compreende que os mais afetados pela imposição de horários sociais são as massas populares, que não podem escolher nem negociar as suas rotinas da mesma forma que as classes privilegiadas. Pensar em uma democracia temporal exige, segundo Freire, uma reeducação social, com consciência histórica, de modo que a organização do tempo seja discutida e as pessoas afetadas sejam ouvidas.

\section{Dominação temporal}

Aprendemos com Edward Palmer Thompson (1967) que o processo de imposição de horários à atividade humana se consolidou no século XIX associado ao processo de afirmação do capitalismo industrial. Na descrição desse autor, desde o século XVI os relógios passaram a sincronizar progressivamente a vida humana, rompendo com as relações temporais presentes na vida rural - a temporização tornouse, assim, abstrata, descolada das necessidades concretas do trabalho rural associ-

\footnotetext{
${ }^{4}$ FREIRE, P. Vídeo particular de evento com diretores e diretoras de escolas de educação infantil e creches do município de São Paulo, ocorrido em 10 abr. 1992, no qual compunham a mesa Paulo Freire e Luiz Menna-Barreto.
} 
ado ao tempo da natureza. Outro autor, Kevin Birth (2012), expande esse olhar sobre o tempo ao expor tanto as origens dos relógios, na ldade Média, como as transformações pelas quais esses aparelhos e o próprio conceito de tempo passaram até o presente, salientando sempre a ideia de constructo, afastando-nos da ilusão da existência de um "tempo em si". Hoje o tempo é o relógio, e isso nos parece natural, dada a disseminação de seu uso. Pergunte-se, por exemplo, quantos relógios uma pessoa tem em sua casa e/ou no trabalho.

Nesse sentido, calendários, horários escolares e férias são exemplos que emergem na sociedade e que tendem a se autojustificar como naturais no cotidiano escolar, o que oculta suas contradições, pois caracterizam justamente os processos de domesticação nesse ambiente.

Há várias décadas temos conversado com autoridades escolares e indagado, informalmente, sobre as origens e fundamentos (justificativas) das rotinas temporais nas escolas. A resposta tem sido invariável: é natural que sejam assim; sempre foram assim. Falta datação nessas respostas, o contexto sociocultural no qual esses horários são propostos/impostos e por que eles acabam sendo mantidos a ponto de se tornarem "naturais". Ora, como escreve Thompson (1967), esses horários foram criados entre outras coisas para atender às demandas do capitalismo industrial vigentes no século XIX. No mesmo texto, esse autor salienta que esses tempos impostos colidiam com a temporalidade do ambiente agrário da Idade Média, quando as atividades eram organizadas por meio de suas relações concretas com a produção das colheitas. Os relógios, abstrações de um tempo descolado dessa concretude, passaram a orientar a vida das populações, cada vez mais concentradas em cidades.

Em seu projeto de ritmanálise, Lefebvre (2004, p. 82) faz uma relação entre a vida cotidiana e os ritmos, partindo de uma análise da criação do tempo. Para ele, a vida cotidiana se baseia no tempo abstrato e quantitativo dos relógios e cronômetros. Segundo esse autor, trata-se de um tempo linear, monótono, que se introduziu pouco a pouco no Ocidente depois das invenções dos relógios e com a entrada desse aparato na vida social. Por ser homogêneo e "dessacralizado", esse tempo se impõe no cotidiano das cidades modernas porque fornece a medida do 
tempo do trabalho. A partir desse momento histórico, a organização do trabalho no espaço-tempo passa a subordinar outros aspectos da vida cotidiana: horas de sono e vigília, momentos de refeições e horas de privacidade, relacionamento familiar, entretenimento, etc. No entanto, afirma Lefebvre (2004, p. 82), a vida ainda é marcada por ritmos cósmicos e vitais, que são cíclicos: dia e noite, meses e estações do ano, e mais precisamente por ritmos biológicos. No cotidiano, isso resulta na interação permanente desses ritmos com os processos repetitivos relacionados ao tempo homogêneo.

Portanto, é relevante e sempre importante ter em vista que os processos de construção e transformação de temporalidades ocorrem de acordo com as circunstâncias socio-histórico-culturais. Esses processos podem ser identificados tanto no plano social como no individual. E nessa perspectiva faz sentido perguntar a que demandas sociais a organização temporal dos espaços escolares atendem e a que custo para os ritmos biológicos dos sujeitos. Mas a resposta não deve ser simples. Na ânsia de privilegiar os ritmos biológicos individuais, não podemos deixar de lado as coletividades, pois a identidade temporal, conforme falamos anteriormente, são construídas biologicamente nas relações sociais e culturais, marcadas pelas lutas contra as diferentes formas de opressão e poder. Um exemplo bem atual, que envolve a temporalidade na educação, consiste nas propostas de educação a distância para etapas consideradas básicas. Tais propostas com vieses liberais acabam ocultando a dimensão social contida na interação viva entre professores e alunos (o tempo do encontro, da troca de experiências, de aprender com o outro), remetendo ao aluno individualmente seus sucessos e fracassos, com a falsa promessa de que assim é possível ganhar tempo ou "otimizar" o tempo que cada um tem disponível. O que mais chama a atenção nessas propostas é a exclusão do convívio social das classes menos favorecidas, dos marginalizados, que está subjacente. É aí que Paulo Freire faz falta, e muita.

Esquece-se que aprendizagem é processo que acontece nas relações interpessoais, sociais, históricas e culturais. (VIGOTSKI, 2010) Além de que, no contexto social e político em que o Brasil se encontra, a proposta de educação a distância para a educação básica traz em seu bojo a premissa de que existe um 
conteúdo cristalizado de conhecimentos de determinadas áreas que pode ser "depositado" nos alunos a qualquer hora e em qualquer lugar - processo que Paulo Freire chama de educação bancária, cujo objetivo principal é a manutenção do status quo. Na concepção de Freire, a educação bancária é inadmissível porque estabelece uma dicotomia entre homem-mundo, como se houvesse uma consciência de mundo espacializada, desconsiderando a característica dos seres humanos como corpos conscientes. (FREIRE, 2014) O contrário disso, na visão de Freire, é a educação libertária, aquela em que todos os sujeitos envolvidos constroem o conhecimento científico a partir do conhecimento de vida que cada um traz para a relação, com base na experiência material, corporal, e também na abstrata, e em acesso pleno ao arcabouço do conhecimento construído coletivamente pela humanidade. (FREIRE, 1996a e 1996b)

Paulo Freire nos convida a considerar momentos como o que estamos vivendo em diversos setores sociais verdadeiros movimentos em prol da alienação, ou seja, movimentos de retrocesso diante das conquistas das últimas décadas, principalmente na educação. Alienação essa que traz um desafio dialético: ao mesmo tempo que implica em dominação/domesticação dos corpos dos alunos, gera a possibilidade (e diríamos, necessidade) de crítica e, portanto, de intenso debate sobre as práticas de liberdade em todas as disciplinas, e não apenas nas chamadas humanidades. Daí a importância de por em evidência um ensino de Biologia, e em especial de Cronobiologia, que seja desalienante. Paulo Freire incomoda, sim, especialmente aqueles cuja defesa da desigualdade social beira o fanatismo. Num mundo globalizado no qual a desigualdade só tem crescido, agora sob o domínio do capital financeiro, que lê o bem-estar social nos valores do Produto Interno Bruto (PIB).

Portanto, entendemos que a contribuição da Cronobiologia para a discussão sobre horários escolares mais compatíveis com os ritmos biológicos de alunos e professores não deve ser vista como argumento para a diluição do encontro nem para a implementação de modelos individualistas. Ao contrário, defendemos o tempo do encontro de modo que ele seja bem aproveitado. Talvez, para isso, a nossa sociedade tenha de compreender a importância da educação e elevá-la a 
outro patamar, negociando horários com outras instituições sociais e definindo temporalidades que priorizem a construção coletiva do conhecimento, deixando de lado também a dicotomia existente entre produção e transmissão do conhecimento. Superemos essa falsa dicotomia, integrando os planos através de seu elo comum, a temporalidade.

\section{Escola: espaço-tempo de ocupação}

Ao falar da pedagogia de Paulo Freire em entrevista a Marisa Vorraber Costa (2007), o sociólogo e educador Miguel Arroyo diz que Freire desenvolveu, com base na experiência em movimentos sociais, uma concepção de educação humanista. Para Freire, segundo Arroyo, a pergunta nuclear do aluno no processo de aprendizagem é: Quem sou eu como ser humano? Arroyo afirma também que a pedagogia de Freire não "entrou" na nossa pedagogia justamente porque no Brasil a educação é vista como preparatória, ou seja, está sempre direcionada para o futuro, seja o próximo ciclo escolar, seja o mercado de trabalho. Nesse aspecto, percebemos também uma tensão entre temporalidades no ambiente escolar - o presente, com suas urgências, e o futuro, cheio de incertezas.

O caráter preparatório a que se refere a crítica de Arroyo não está conectado com a ideia de ser humano como devir, preconizada por Freire, justamente porque o foco da educação que se difundiu no país não está no ser humano, mas sim no processo e, em última instância, no mercado. Nesse caso, o descompasso deixa uma brecha quase intransponível entre a idealização escolar e a realidade. Em seu livro Imagens quebradas: trajetórias e tempos de alunos e mestres (2009), Miguel Arroyo traça um panorama da frustração de educadores diante da interrogação sobre o que está acontecendo nas escolas e na docência. Um dos pontos cruciais nesse incômodo são as trajetórias e as temporalidades dos estudantes, que, segundo relatos de professores entrevistados pelo autor, muitas vezes dificultam a prática pedagógica. Baseado na abordagem freireana, Arroyo propõem que, quando os objetivos pedagógicos se voltam para os sujeitos da ação educativa (educandos e educadores), outras sensibilidades se instauram. E é nos 
agrupamentos, nos convívios entre pares de vivências e de percursos que é possível sincronizar os tempos dos sujeitos. Para Arroyo (2009), a dimensão espacial é um dos traços das culturas juvenis e adolescentes, sendo a escola um espaço de ocupação, de convívios e de sociabilidade. Assim, entendemos que organizar os tempos escolares - horários de entrada e saída, férias, duração das aulas, entre outros aspectos - é zelar para que os momentos nesses espaços sejam ricos e intensos para a coletividade, respeitando as subjetividades a partir de consensos discutidos democraticamente.

Arroyo (2009) destaca a dificuldade de professores em lidar com a dimensão corpórea dos alunos, o que inclui a dificuldade de compreensão dos ritmos desses alunos e dos próprios ritmos. Em uma educação exclusiva para uma elite privilegiada, não havia diversidade nem desafios tão materiais em sala de aula. Diante de uma plateia heterogênea como a que surgiu, principalmente nas escolas públicas brasileiras, nas últimas décadas, professores se sentem desafiados por corpos que "não são dóceis" e não estão "domesticados", e o cumprimento do horário escolar, a permanência na sala de aula e até mesmo o sono na sala de aula passam a ser sinônimos de indisciplina. Para Michel Foucault, "É dócil um corpo que pode ser submetido, que pode ser utilizado, que pode ser transformado e aperfeiçoado" (FOUCAULT, 1987, p. 118). Esse autor ensina que a obsessão pelo corpo como objeto e alvo de poder surge na época clássica, quando se propagou a ideia de homem-máquina, que teve início com escritos de Descartes, que se baseavam em ideias anátomo-metafísicas, sempre com ênfase no ritmo, na relação espaço-temporal.

[...] A modalidade enfim: implica numa coerção ininterrupta, constante, que vela sobre os processos da atividade mais que sobre seu resultado e se exerce de acordo com uma codificação que esquadrinha ao máximo o tempo, o espaço, os movimentos. Esses métodos que permitem o controle minucioso das operações do corpo, que realizam a sujeição constante de suas forças e lhes impõem uma relação de docilidade-utilidade, são o que podemos chamar as "disciplinas". Muitos processos disciplinares existiam há muito tempo: nos conventos, nos exércitos, nas oficinas também. Mas as disciplinas se tornaram no decorrer dos séculos XVII e XVIII fórmulas gerais de dominação. (FOUCAULT, 1987, p. 118) 
A dominação dos corpos não se fundamenta na relação de apropriação, característica da escravidão, mas sim na "elegância da disciplina", que dispensa a relação custosa e violenta e obtêm efeitos de utilidade semelhantes. (FOUCAULT, 1987) Os efeitos dessa dominação, que se estabelece no período clássico, como ensina o filósofo francês, culminam na Modernidade, com a Revolução Industrial, e caracterizam o modelo de indústrias do início do século XX, muito bem caracterizados no cinema por Charles Chaplin, em Tempos Modernos (1936), em que o homem é apresentado como uma extensão da máquina, e o seu corpo passa a funcionar no ritmo da fábrica.

Nas sociedades capitalistas contemporâneas, no âmbito social, criam-se rotinas que tendem a manter as pessoas constantemente ocupadas em produzir e consumir. E essas rotinas afetam o tempo do trabalho e da educação de modos diferentes. No caso do trabalho, aquele modelo de jornada com duração de oito horas por dia, seis dias por semana, que se estabeleceu como uma conquista pósRevolução Industrial, por exemplo, ocupava a maior parte do nosso tempo, mas ainda considerava a necessidade do tempo de descanso. Observamos no cenário mais recente, como bem descreve Jonathan Crary (2016), que essa condição de trabalho vem sendo alterada. Muitas vezes, com o nome de flexibilização e com o revestimento de um suposto respeito pelos ritmos individuais, um falso respeito às identidades temporais, ocorre a precarização das relações de trabalho.

Essa situação gera um processo brilhantemente descrito por Byung-Shul Han (2017) no qual o controle das horas de trabalho, antes externo, como disse Michel Foucault (1987), passa a ser interno, ou seja, ele é incorporado pelo próprio cidadãotrabalhador, que agora exerce o controle de suas atividades, de onde nasce e prolifera também o sentimento de culpa por não produzir mais e mais. No plano individual, as patologias hoje têm uma de suas vertentes causais nos conflitos temporais aos quais estamos submetidos. O exemplo atual mais evidente é o crescimento generalizado de quadros de depressão - que emergem, entre outros fatores, de dessincronizações internas (ritmos dos órgãos do nosso corpo) e externas, entre nossos corpos e os tempos exigidos socialmente.

O fato bastante conhecido da existência de importantes diferenças 
individuais nos quadros patológicos e nas manifestações de saúde permite a noção de que cada um de nós constrói sua temporalidade (a sua identidade temporal, como evidenciamos anteriormente), compondo uma diversidade que resiste a tentativas de imposições de normalidades.

Atualmente, chamam a atenção na escola os corpos infantis inquietos e os corpos adolescentes e juvenis indisciplinados. Há também corpos presentes na escola que, mesmo quando estão em silêncio, gritam por meio das marcas da sua história: raça, gênero, condições sociais. (ARROYO, 2009) De acordo com a ritmoanálise proposta por Lefebvre e com a abordagem temporal presente na obra de Paulo Freire, observamos a dominação temporal presente no ambiente escolar e a consequente padronização das pessoas, com a imposição de padrões de normalidade. O pensamento que sustenta a prática da modelagem é a relutância em aceitar as coisas como elas são, é a dificuldade de trabalhar com a diversidade, principalmente em larga escala, e a necessidade de padronizar para facilitar a manipulação e o controle de comportamentos e, em última instância, o controle da vida.

Há um sinal dos tempos, entre outros, que me assusta: a insistência com que, em nome da democracia, da liberdade e da eficácia, se vem asfixiando a própria liberdade e, por extensão, a criatividade e o gosto da aventura do espírito. A liberdade de mover-nos, de arriscarnos vem sendo submetida a uma certa padronização de fórmulas, de maneiras de ser, em relação às quais somos avaliados. É claro que já não se trata de asfixia truculentamente realizada pelo rei despótico sobre seus súditos, pelo senhor feudal sobre seus vassalos, pelo colonizador sobre os colonizados, pelo dono da fábrica sobre seus operários, pelo Estado autoritário sobre os cidadãos, mas pelo poder invisível da domesticação alienante que alcança a eficiência extraordinária no que venho chamando "burocratização da mente". Um estado refinado de estranheza, de "autodemissão" da mente, do corpo consciente, de conformismo do indivíduo, de acomodação diante de situações consideradas fatalistamente como imutáveis. E a posição de quem encara os fatos como algo consumado, como algo que se deu porque tinha que se dar da forma como se deu, é a posição, por isso mesmo, de quem entende e vive a História como determinismo e não como possibilidade. (FREIRE, 1996a, p. 43)

Esse brilhante trecho de Pedagogia da autonomia, de Paulo Freire (1996a), sintetiza bem o que viemos apresentando até aqui. O controle do tempo está 
intimamente atrelado à alienação dos processos de humanização, à falta de consciência corporal tanto em seu aspecto individual - construção de uma identidade biossociocultural - como no aspecto de corpo coletivo - consciência de classe e das situações opressoras que nos atingem, sejam elas constituídas ao longo de processos históricos, sejam instituídas nas rotinas às quais estamos submetidos na escola, no trabalho e até mesmo no lazer. Já na década de 1990, em sua última obra publicada em vida, Freire sinalizava um aspecto que, agora na segunda década do século XXI, tem sido abordado por autores críticos e filósofos que se dispõem a compreender as novas configurações sociais a partir das relações temporais e das alterações profundas nos modos de interação, impulsionadas em grande parte pelas possibilidades de encurtamento de distâncias e pela aceleração de processos de comunicação em todo o globo. Trata-se de um ritmo de vida que se configura cada vez mais impróprio para um corpo humano. Incomodado com a supremacia do mercado em relação aos seres humanos, Paulo Freire, com sua radicalidade mais do que necessária nos tempos atuais, propõe:

Há um século e meio Marx e Engels gritavam em favor da união das classes trabalhadoras do mundo contra sua espoliação. Agora, necessária e urgente se fazem a união e a rebelião das gentes contra a ameaça que nos atinge, a da negação de nós mesmos como seres humanos submetidos à "fereza" da ética do mercado. (FREIRE, 1996a, p. 48)

Pois é justamente na leitura crítica do marxismo que nós entendemos que Paulo Freire e Henri Lefebvre se encontram, sobretudo na leitura da construção de um futuro criativo e livré.

\section{Conclusão}

O processo de desalienação proposto por Paulo Freire nos leva a pensar em modos de ensino de Biologia em geral e da Cronobiologia em particular que levem

\footnotetext{
${ }^{5}$ MENNA-BARRETO (2019) apresentou uma conferência que ilustra bem esse encontro durante o Congresso Internacional On-line de Estudos Sobre Culturas, que pode ser assistido em vídeo disponível em:

https://drive.google.com/file/d/1WAnROmcYtyCza2TwXIbxr1_hZ8MFxnIV/view? usp=sharing
} 
os estudantes a uma convivência mais íntima com o próprio corpo e com seus ritmos. Nossa expectativa é que essa consciência contribua para a construção da consciência crítica preconizada por Paulo Freire. O convite à reflexão crítica presente nos escritos de Paulo Freire, mais do que o merecido reconhecimento, deve se constituir em desafio à nossa criatividade e empenho em construir um futuro mais igualitário para nossa sociedade. Cidadãos conscientes dos tempos de seus corpos são e serão menos domesticáveis, e mais senhores de seus futuros.

Entendemos que a contribuição mais relevante de Paulo Freire é o convite contido em suas ideias para que os agentes, professores, pais e estudantes se constituam em autores do próprio destino e, para isso, o ambiente escolar é um dos cenários mais propícios a esse esforço.

Verificamos a aproximação da proposta de ritmanálise de Henri Lefebvre (1992), de entender o tempo e o espaço como indissociáveis, com a visão de Paulo Freire de conceber a escola como espaço de convivência e troca de experiências, sendo que essa convivência, no nosso entendimento, deve ser planejada física e temporalmente, contemplando todos os sujeitos envolvidos em sua integralidade, pois é no ambiente escolar, entre outros tantos lugares, que uma sociedade será construída democraticamente. 


\section{Referências Bibliográficas}

ARROYO, M. Imagens quebradas: trajetórias e tempos de alunos e mestres.

Petrópolis: Vozes, 2009.

BIRTH, K. K. Objects of Time: How Things Shape Temporality. New York: Palgrave MacMillan. 2012.

CARVALHO-MENDES, R. P. Análise dos parâmetros rítmicos e de sono, cronotipo e jetlag social em adolescentes: relações com o gênero, turno escolar, atividades noturnas e desempenho cognitivo.Tese de doutorado em Neurociências e Comportamento. Instituto de Psicologia. Universidade de São Paulo, São Paulo, 2019.

CHAPLIN, C. Tempos modernos (Modern Times, 1936. Duração: 87 min). Continental Home Vídeo. Coleção Carlitos, v. 5.

COSTA, M. V. A escola tem futuro? Rio de Janeiro: Lamparina, 2007.

CRARY, J. 24/7: capitalismo tardio e os fins do sono. São Paulo: Ubu, 2016.

FOUCAULT, M. Os corpos dóceis. In: Vigiar e punir: nascimento da prisão. Trad. de Raquel Ramalhete. Petrópolis, Vozes, 1987.

FREIRE, P. Educação como prática da liberdade. 22. ed. Rio de Janeiro: Paz e Terra, 1996a.

. Pedagogia da autonomia: saberes necessários à prática educativa. São

Paulo: Paz e Terra, 1996b.

2014.

. Pedagogia do oprimido. 57 ed. rev. e atual. Rio de Janeiro: Paz e Terra,

HAN, B. Sociedade do cansaço. Rio de Janeiro: Vozes, 2017.

KRASILCHIK, M. O professor e o currículo das ciências. São Paulo: Edusp, 1987.

LEFEBVRE, H. Éléments de Ritmanalyse. Paris: Syllepse, 1992.

Elements of Rhythmanalysis: Space, Time and Everyday life. New

York/London: Continuum, 2004.

. Problèmes actuels du marxisme. Paris: PUF, 1963.

LOUZADA, F.; MENNA-BARRETO, L. O sono na sala de aula: tempo escolar e tempo biológico. Rio de janeiro: Vieira\&Lent, 2007. 
MATURANA, H.; VARELA, F. De maquinas y seres vivos. Autopoiesis: la organización de lo vivo. Santiago: Editorial Universitaria Lumen, 1974.

MENNA-BARRETO, L. Um espaço para o tempo na leitura dos corpos. Congresso Internacional On-line de Estudos sobre Culturas. Centro Latino-Americano de Estudos em Cultura (CLAEC), out. 2019, Foz do Iguaçu. Acesso em 5 de dezembro de 2019. Disponível em:

https://drive.google.com/file/d/1WAnROmcYtyCza2TwXIbxrl_hZ8MFxn1 V/view? us $\mathrm{p}=$ sharing

NATIONAL SLEEP FOUNDATION. Disponível em: < https://www.sleepfoundation.org/articles/school-start-time-and-sleep>. Acesso em: 10 set. 2019.

PITANO, S. Sujeito social. In: STRECK, D. R.; REDIN, E.; ZITKOSKI, J. J. (Org.). Dicionário Paulo Freire. 4 ed. rev. ampl. Belo Horizonte: Autêntica, 2018.

PASSOS, L. A. Tempo. In: STRECK, D. R.; REDIN, E.; ZITKOSKI, J. J. (Org.). Dicionário Paulo Freire. 4 ed. rev. ampl. Belo Horizonte: Autêntica, 2018.

SILVA, H. G.; INFANTE-MALACHIAS, M. E. Biologia da autonomia: a importância da temporalidade de Freire e do fenômeno histórico de Maturana para o ensino de biologia. Inter-Ação, Goiânia, v. 42, n. 1, p. 159-175, jan./abr. 2017. Disponível em: <http://dx.doi.org/10.5216/ia.v42i1.41637>. Acesso em: 17 set. 2019.

THOMPSON, E. P. Time, Work-Discipline, and Industrial Capitalism, Past \& Present, Oxford University Press, n. 38 (1967), p. 56-97.

VIGOTSKI, L. S. A formação social da mente: o desenvolvimento dos processos psicológicos superiores. São Paulo: Martins Fontes, 2010. 